\title{
Sosialisasi Pengelolaan Sampah Sebagai Bahan Bakar untuk Pembangkit Listrik Tenaga Sampah (PLTSa) dengan Sistem Strategic Partner
}

\author{
A B R Indah ${ }^{1 *}, \mathrm{~S}$ Bahri, Mulyadi ${ }^{1}, \mathrm{R} \mathrm{Hanafi}^{1}, \mathrm{~S} \mathrm{Asmal}^{1}, \mathrm{~F} \mathrm{Mardin}^{1}$, M Rusman ${ }^{1}$, I Bakri ${ }^{1}$, Nilda ${ }^{1}$, \\ D R Mudiastuti ${ }^{1}$, S Mangenre ${ }^{1}$, I Setiawan ${ }^{1}$, S Parenreng ${ }^{1}$, M A Darmawan ${ }^{1}$, K Amar ${ }^{1}$, N I \\ Syamsul $^{1}$ \\ Departemen Teknik Industri, Fakultas Teknik Universitas Hasanuddin ${ }^{1}$ \\ a.besseriyani@gmail.com*
}

\begin{abstract}
Abstrak
Kepadatan penduduk menjadi salah satu pemicu semakin meningkatnya volume sampah termasuk sampah plastik. Sampah merupakan salah satu masalah yang perlu diperhatikan khususnya di daerah perkotaan. Sampah dapat dijadikan sebagai sumber energi terbarukan (renewable energy) yang tersedia sangat melimpah namun kendalanya adalah hingga kini belum dimanfaatkan secara optimal. Namun saat ini, pola pemikiran tersebut sudah mulai ditepis setelah diterapkannya PLTSa (Pembangkit Listrik Tenaga Sampah) di kawasan pembuangan sampah dan akan meningkatkan kepedulian masyarakat terhadap lingkungannya. Ada beberapa metode pengelolaan yang dapat dilakukan untuk menjadikan sampah sebagai bahan bakar untuk menghasilkan listrik yaitu, proses konversi thermal dan proses konversi biologis. Proses pengelolaan sampah sebagai bahan bakar akan lebih baik lagi jika dilakukan dengan metode strategic partner. Dinas Lingkungan Hidup Kabupaten Pangkep telah menjalankan program bank sampah agar sampah dapat terkordinir dengan baik di beberapa kecamatan. Masalah yang dihadapi oleh bank sampah kabupaten Pangkep adalah perilaku memilah sampah yang masih sulit, hasil pemilahan sampah belum dimanfaatkan secara maksimal, dan belum ada pemahaman terkait pengelolaan sampah dengan mekanisme PLTSa. Untuk meningkatkan pengetahuan Bank sampah terkait pemanfaatan sampah dengan mekanisme PLTSa maka dilakukan sosialisasi dengan luaran pengelola bank sampah dapat mengetahui potensi sampah menjadi bahan bakar PLTSa, pengelola bank sampah dapat mengetahui mekanisme kerja sama mitra dalam mewujudkan PLTSa, dan pedoman untuk membuat rancangan sampah sebagai bahan bakar PLTSa. Kegiatan ini di laksanakan di Badan Lingkungan Hidup Kab. Pangkep dengan peserta perwakilan beberapa bank sampah di kab. Pangkep.
\end{abstract}

Kata Kunci: Sampah; Renewable Energy; PLTSa; Strategic Partner; Bank Sampah.

\begin{abstract}
Population density is one of the triggers for the increasing volume of waste including plastic waste. Waste is one problem that needs attention, especially in urban areas. Waste can be used as a source of renewable energy which is very abundant but the obstacle is that until now it has not been optimally utilized. However, at present, this pattern of thinking has begun to be pushed aside after the implementation of PLTSa in the garbage disposal area and will increase public awareness of the environment. There are several management methods that can be used to make waste as fuel to generate electricity, namely, the thermal conversion process and the biological conversion process. The process of managing waste as fuel will be even better if it is carried out using a strategic partner method. The Environmental Agency of Pangkep Region has implemented a waste bank program so that waste can be well coordinated in several districts. The problem faced by the waste bank in Pangkep region is the behavior of sorting waste which is still difficult, the results of sorting waste have not been fully utilized, and there is no understanding regarding waste management using the PLTSa mechanism. To increase the knowledge of the waste bank regarding the utilization of waste with the PLTSa mechanism, socialization is carried out with the output of the waste bank manager to find out the potential for waste to become PLTSa fuel, the waste bank manager can find out the mechanism of partner cooperation in realizing PLTSa, and guidelines for designing waste as fuel. PLTSa. This activity was carried out at the Environmental Agency of Pangkep Region with participants representing several waste banks in Pangkep Region.
\end{abstract}

Keywords: Waste; Renewable Energy; PLTSa; Strategic Partner; Waste Bank. 


\section{Pendahuluan}

Pertumbuhan penduduk memiliki pengaruh yang cukup besar terhadap volume sampah yang dihasilkan masyarakat, hal ini disebabkan karena sampah merupakan sisa aktivitas masyarakat dalam kehidupannya sehari-hari. Semakin tinggi pertumbuhan jumlah penduduk maka semakin tinggi pula laju pertumbuhan yang terjadi. Hal ini berbanding lurus dengan bertambahnya volume sampah. Karena meningkatnya kepadatan penduduk menyebabkan semakin kurangnya lahan di daerah perkotaan sementara volume sampah semakin meningkat. Hal ini menyebabkan sampah salah satu masalah yang perlu diperhatikan khususnya di daerah perkotaan. Selain itu, sampah juga harus diperhatikan cara pengelolaannya sehingga tidak menjadi masalah bagi lingkungan. Pada hakikatnya keberadaan sampah tidak hanya menimbulkan masalah. Akan tetapi, sampah bisa menjadi potensi sumber energi terbarukan (renewable energy) yang tersedia sangat melimpah namun kendalanya adalah hingga kini belum dimanfaatkan secara optimal.

Menurut UU No.18 tahun 2008 pengolahan sampah telah diatur sebagaimana mestinya demi terwujudnya peningkatan kesehatan masyarakat dan kebersihan lingkungan serta menjadikan sampah sebagai sumber daya. Dalam undang-undang tersebut disebutkan juga bahwa, pengolahan sampah yang dimaksud adalah sebagai suatu kegiatan yang sistematis, menyeluruh, dan berkesinambungan yang meliputi pengurangan dan penanganan sampah. Namun demikian cara sederhana kumpul-angkut-buang masih banyak diterapkan di Indonesia. Namun saat ini sistem pengolahan sampah telah berkembang bahkan hingga dapat digunakan sebagai bahan bakar untuk pembangkit seperti PLTSa yang memiliki kapasitas kecil. Dahulu sampah merupakan barang sisa yang dianggap tidak memiliki manfaat, sehingga untuk mengelola sampah dibutuhkan biaya untuk mengelolanya. Oleh karena itu, semakin besar volume sampah maka semakin besar biaya yang dikeluarkan untuk mengelolanya. Namun saat ini, pola pemikiran tersebut sudah mulai ditepis setelah diterapkannya PLTSa di kawasan pembuangan sampah dan akan meningkatkan kepedulian masyarakat terhadap lingkungannya.

Saat ini sistem pengelolaan sampah di Indonesia dilakukan secara konvensional dengan beberapa metode, yaitu metode open dumping (tumpukan) dan sanitary landfill (timbunan), dengan menggunakan metode ini sampah dibiarkan ditumpuk dilokasi tempat pembuangan akhir (TPA) sedangkan untuk metode timbunan, sampah yang telah ditumpuk kemudian di timbun dengan tanah. Dengan menggunakan metode ini maka timbul beberapa masalah diantaranya kebutuhan lahan untuk proses pengelolaan akan meningkat seiring dengan makin meningkatnya volume sampah. Dengan adanya masalah tersebut maka para ahli mulai memikirkan cara pengelolaan yang lebih efektif, salah satunya adalah menjadikan sampah sebagai sumber energi contohnya adalah energi listrik untuk PLTSa (Sihite, 2018).

Ada beberapa metode pengelolaan yang dapat dilakukan untuk menjadikan sampah sebagai bahan bakar untuk menghasilkan listrik yaitu, proses konversi thermal dan proses konversi biologis. Proses konversi thermal pada dasarnya memiliki prinsip kerja yang hampir sama dengan PLTU. Namun dikarenakan perbedaan bahan bakar, maka pembangkit ini memiliki komponen tambahan berupa tempat pengolahan bahan bakarnya sendiri sebelum memanfaatkan teknologi insenerasi, pirolisis, dan gasifikasi. Sedangkan proses konversi biologis adalah dengan Anaerobik Digestion dan Landfill gasification Dalam menentukan proses pembangkitan harus memilih teknologi yang paling tepat untuk dijadikan solusi atas permasalahan sampah bergantung pada kondisi daerahnya masing-masing. 
Proses pengelolaan sampah sebagai bahan bakar akan lebih baik lagi jika dilakukan dengan metode strategic partner. Strategic partner juga biasa dikenal dengan sebutan kemitraan strategis. Dalam hal ini dalam proses pengelolaan sampah menjadi sumber energi bagi PLTSa dibuat dengan membangun hubungan kerjasama dengan pihak yang berhungan dengan PLTSa baik itu swasta maupun pemerintahan. Strategic partner merupakan cara yang efektif untuk berbagi keahlian, mendapatkan modal, dan sumber daya.

\section{Latar Belakang Teori}

Berdasarkan masalah yang dihadapi oleh bank sampah Kab. Pangkep sesuai dengan yang telah diuraikan di atas maka, dibutuhkan suatu sosialisasi terkait pengelolaan sampah sebagai bahan bakar untuk pembangkit tenaga listrik tenaga sampah.

1. Pengolahan Sampah ada beberapa tahapan untuk proses konversi thermal yaitu :

a. Pengumpulan

Pada tahapan ini sampah akan dikumpulkan, kemudian dilakukan pengeringan (pengurangan jumlah air) dengan cara di press menggunakan mesin press. Selanjutnya sampah tersebut dipisahkan antara yang baru datang dengan yang telah di press. Sampah yang telah di press ini merupakan treatment pertama pengeringan dimana ditempatkan pada ruangan yang suhunya diatur.

b. Pemindahan

Pemindahan dilakukan bagi sampah yang sudah di press dan dikeringkan yang dikerjakan pada tahap pertama (Flail Mill) untuk dibawa ke Flail Mill.

c. Pengelompokan dan pemisahan

Pada tahap ini sampah dikelompokkan dan dipisahkan dengan menggunakan alat Magnetic Separator, belt conveyor, Shredder. Sampah yang semula basah dan tidak berukuran serta bercampur antara organik dan unorganik sekarang sudah berubah menjadi serbuk kering yang siap dijadikan bahan bakar untuk memanaskan boiler.

d. Perubahan dari sampah ke energi

Bahan bakar tersebut selanjutnya dimasukkan ke ruang pembakaran (chamber).

e. Pengolahan kimia fisika

Selanjutnya sisa bahan bakar dalam bentuk padat dan cair akan diolah secara kimia fisika yang dapat dijadikan sebagai bahan bakar kembali, granulate, dan lain sebagainya.

f. Pengolahan biologi

Pada tahap ini sampah-sampah basah yang tidak ekonomis bila dijadikan bahan bakar akan diolah secara biologis untuk dijadikan komposs.

g. Pengolahan khusus

Pada tahapan ini sampah-sampah yang tidak dapat didaur ulang akan diberikan perlakuan khusus. Misalkan sampah-sampah plastik akan dicincang menjadi bentuk-bentuk pallete.

h. Pembuatan material

Pada bagian ini pallete-pallete plastik akan dibuat menjadi peralatan-peralatan rumah tangga yang terbuat dari plastik. Untuk granulate dapat dibuat paving block, dinding akuistik dan dinding beton siap pasang.

2. Pembangkit Listrik Tenaga Sampah (PLTSa)

Pembangkit listrik tenaga sampah merupakan pembangkit listrik yang memanfaatkan sampah sebagai bahan bakar. Sampah ini nantinya akan digunakan untuk memanaskan air dalam boiler. Uap panas yang dihasikan boiler ini dimasukkan ke turbin uap yang akan memutar 
generator sehingga menghasilkan energi listrik. Agar dapat diketahui besarnya daya listrik yang dihasilkan Pembangkit Listrik Tenaga Sampah (PLTSa) ada beberapa hal yang harus dilakukan :

1. Penghitungan Jumlah Timbulan Sampah

Jumlah timbulan sampah ini perlu diketahui untuk menghitung jumlah stok sampah yang kelak nantinya dijadikan bahan bakar dan akan berhubungan dengan kelangsungan pasokan daya listrik dan jumlah energi yang akan dihasilkan (kWh).

2. Pengujian kalor

Sampah yang diperoleh dari pasar, pemukiman, pertokoan, jalan raya dan lain sebagainya nantinya akan menyatu di Tempat Pengumpulan Sementara (TPS) ataupun di Tempat Pengumpulan Akhir (TPA). Sampel sampah yang diambil akan diuji kalor dan kandungan gas yang dihasikannya.

3. Perhitungan Jumlah Kalor

Dari hasil uji kalor sampah yang dilakukan, maka akan dihitung jumlah kalor total yang dihasilkan timbulan sampah.

4. Perhitungan Kapasitas Boiler

Kalor total yang dihasilkan ini akan digunakan untuk menentukan kapasitas boiler dan jumlah air yang akan dipanaskan untuk dijadikan uap.

5. Perhitungan Kapasitas Turbin

Setelah kapasitas boiler diperoleh selanjutnya akan dapat dihitung kapasitas turbin yang akan digunakan untuk memutar generator.

6. Perhitungan Kapasitas Generator

Dari data turbin yang diperoleh dapat ditentukan jenis dan kapasitas generator, apakah akan digunakan beberapa unit kecil atau satu unit besar.

7. Perhitungan Ekonomis

Perhitungan ekonomis in dilakukan untuk melihat total biaya yang dikeluarkan untuk pembangunan PLTSa ini, waktu pengembalian, nilai sekarang serta tarif listrik. Berikut diberikanSecara sederhana dapat diilustrasikan pengolahan sampah dengan metode pembakaran (Monice \& Perinov, 2016):

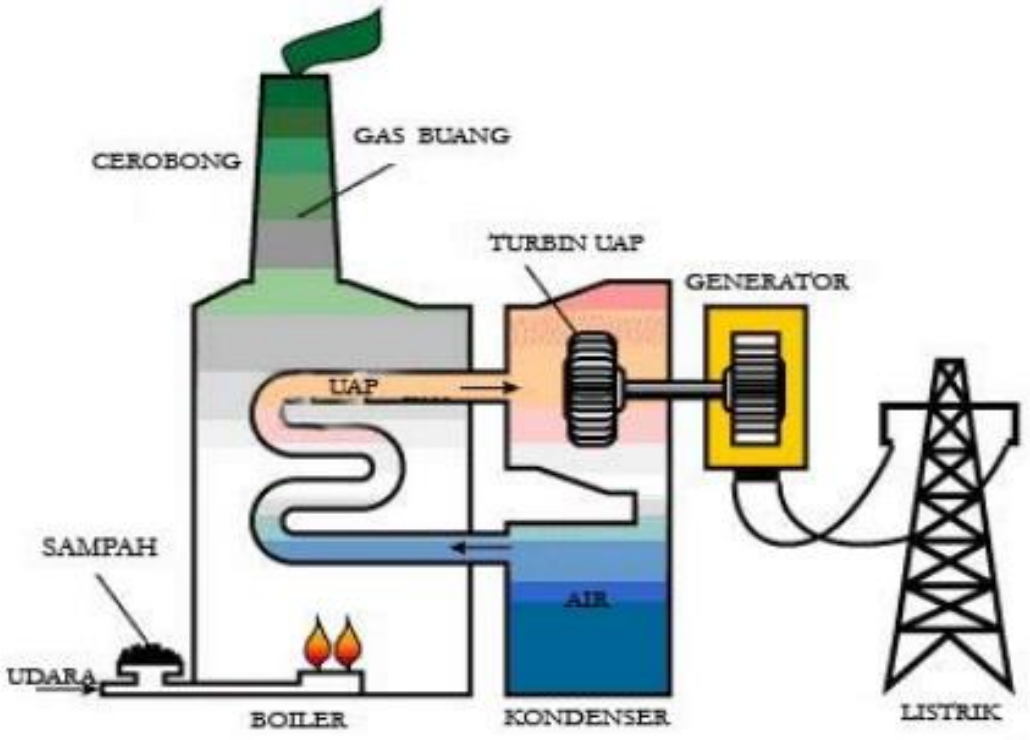

Gambar 1. Proses Sederhana PLTSa (Monice \& Perinov, 2016) 
3. Gambaran Strategic Partner PLTsa

Strategic partner adalah kerjasama (partnerships) antara dua atau lebih perusahaan atau unit bisnis yang bekerjasama untuk mencapai tujuan yang signifikan secara strategis yang saling menguntungkan. Strategic partner dalam hal pengelolaan sampah menjadi bahan bakar listrik telah diatur dalam PERPRES No. 35 Tahun 2018 tentang Percepatan Pembangunan Instalsasi Pengolah Sampah menjadi Energi Listrik berbasis Teknologi Ramah Lingkungan. Dalam Perpres tersebut pada Pasal 5 ayat 1 menyatakan bahwa Pemerintah Daerah Kabupaten/ Kota secara mandiri atau bersama-sama dapat bermitra dengan Pengelola sampah dalam penyelenggaraan pengelolaan sampah. Skema kerja sama dapat dilakukan bersama Badan Usaha Milik Daerah (BUMD) atau Badan Usaha Milik Negara (BUMN) (Indonesia, 2018). Berdasarkan Perpres No. 35 Tahun 2018 maka salah satu BUMN penyedia listrik yaitu PT. PLN (Persero) telah membuat contoh skema kerjasama seperti pada gambar di bawah ini :

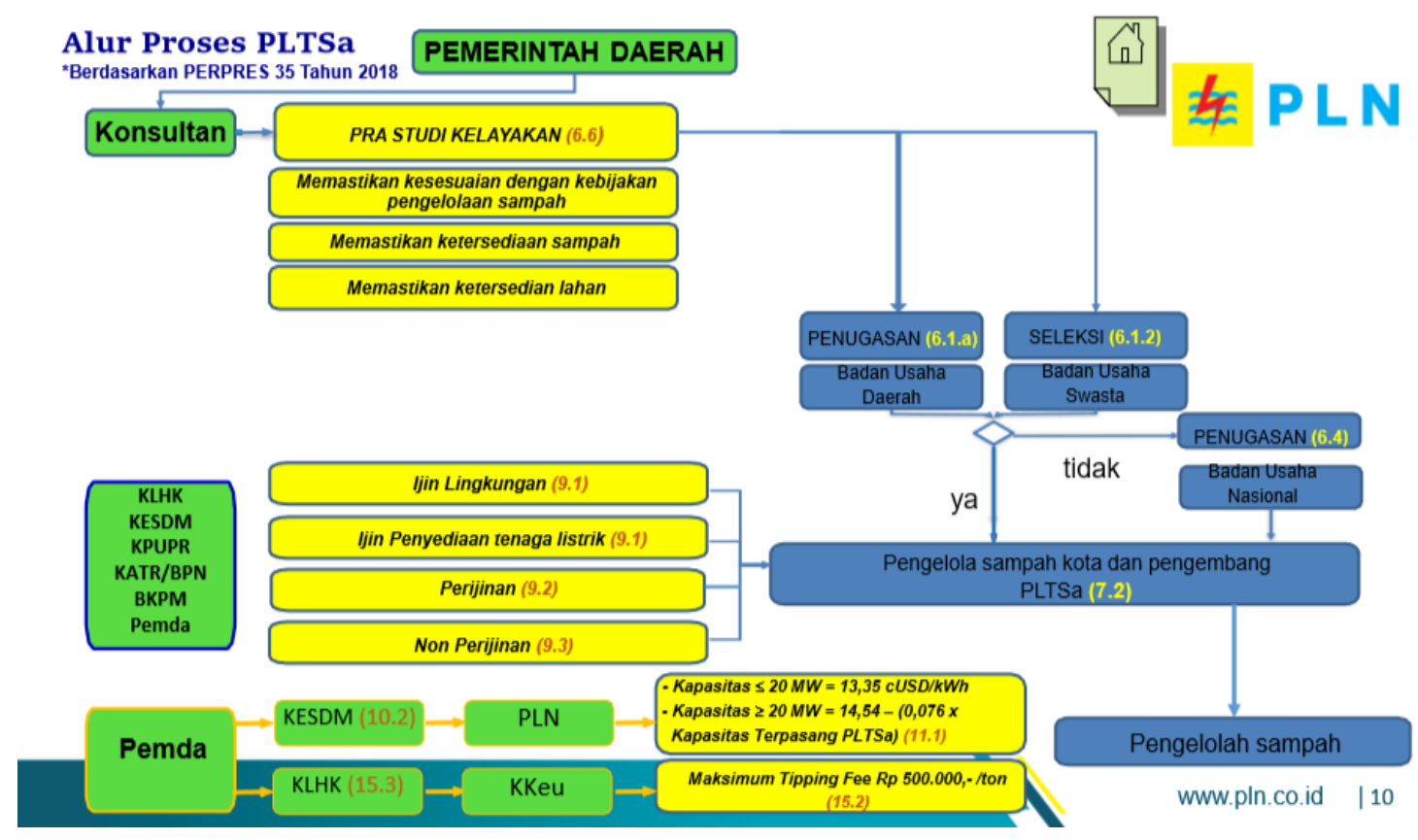

Gambar 2. Alur Proses PLTSa berdasarkan PERPRES 35 Tahun 2018 (Mulyono, 2018)

4. Permasalahan Mitra

Hampir di setiap daerah memiliki masalah dalam hal pengelolaan sampah. Program bank sampah merupakan suatu sistem pengelolaan sampah secara kolektif dengan menggunakan prinsip daur ulang. Dinas Lingkungan Hidup Kabupaten Pangkep telah menjalankan program bank sampah agar sampah dapat terkordinir dengan baik di beberapa kecamatan. Adapun beberapa masalah yang dihadapi oleh bank sampah kabupaten Pangkep adalah :

1. Perilaku memilah sampah di Pangkep masih sulit dengan perilaku membiasakan diri membuang sampah sesuai jenis.

2. Proses pengelolaan sampah dengan cara memilah sampah organik dan anorganik tanpa memaksimalkan proses daur ulang sampah.

3. Hasil pemilahan sampah belum dapat dimanfaatkan secara maksimal menjadi produk yang lebih ekonomis seperti pupuk kompos atau produk-produk kerajinan. 
4. Belum ada pemahaman dan pengetahuan bahwa pengelolaan sampah dapat dilakukan dengan menghasilkan bahan bakar menjadi energi listrik untuk PLTSa.

Dari uraian permasalahan di atas, maka penting dilakukan sosialisasi terkait pengelolaan sampah untuk dapat meningkatkan pengetahuan dan pemahaman khususnya stakeholder pada bank sampah kab. Pangkep sehingga diharapkan sistem pengelolaan sampah dapat dilakukan secara maksimal, terlebih sampai saat ini stakeholder belum memahami sistem pengelolaan sampah yang dapat dijadikan sebagai sumber energi listrik. Dan dengan sumber energi listrik tersebut dapat dilakukan strategic partner dengan melakukan kerjasama dengan mitra-mitra yang terkait sehingga proses pengelolaan sampah bernilai ekonomis.

\section{Metode Untuk Menangani Permasalahan}

Tahapan bentuk sosialisasi Pengelolaan Sampah menjadi bahan bakar PLTSa dengan strategic partner adalah sebagai berikut:

a. Melakukan survey lapangan pada objek lokasi pengabdian yang bertempat di Kabupaten Pangkep.

b. Melakukan diskusi terkait potensi sampah menjadi bahan bakar untuk menghasilkan energy listrik dengan Ketua Bank Sampah Teras Kab. Pangkep.

c. Mengadakan penyuluhan kepada pengelola Bank Sampah di kabupaten Pangkep tentang potensi pengelolaan sampah menjadi bahan bakar untuk PLTSa.

d. Mensosialisasikan skema strategic partner dalam mengembangkan pengelolaan sampah untuk menjadi bahan bakar PLTSa.

Penyuluhan tentang Pembangkit Listrik Tenaga Sampah (PLTSa) sebagai berikut :

a. Penyuluhan ini akan diawali dengan penjelasan tentang Proses Pengelolaan Sampah untuk menjadi bahan bakar dengan proses konversi thermal.

b. Penyuluhan selanjutnya tentang Penjelasan Proses PLTSa secara sederhana dengan konversi thermal.

c. Penyuluhan tentang Strategic Partner Pengelolaan sampah menjadi energi listrik yang tertuang pada Perpres No. 35 Tahun 2018.

\section{Target Capaian}

Kegiatan Sosialisasi terkait pengelolaan sampah menjadi bahan bakar untuk PLTSa yang dilakukan di kab. Pangkep dengan peserta dari perwakilan beberapa bank sampah diharapkan dapat mencapai target capaian yang diantaranya adalah :

1. Pengelola bank sampah Kab. Pangkep mengetahui dan memahami potensi sampah yang dapat dijadikan sebagai bahan bakar PLTSa

2. Pengelola bank sampah Kab. Pangkep dapat mengetahui dan memahami potensi kerja sama dengan mitra yang terkait dengan PLTSa berdasarkan Perpres No. 35 Tahun 2018.

3. Sebuah pedoman untuk membuat rancangan pengelolaan sampah sebagai bahan bakar PLTSa.

\section{Implementasi Kegiatan}

Beberapa kota di Indonesia seperti Surabaya dan Bali sudah menerapkan pengelolaan sampah yang dimanfaatkan menjadi bahan bakar listrik. Sampah yang digunakan adalah sampah plastik dan ranting kayu. Beberapa daerah di Indonesia belum mengetahui potensi pemanfaatan sampah yang dapat dijadikan sebagai sumber energi listrik khususnya PLTSa. Oleh karena itu, Fakultas 
Teknik Unhas melaksanakan Sosialisasi yang difokuskan pada beberapa bank sampah di Kab. Pangkep. Tema sosialisasi yang dibawakan adalah "Sosialisasi Pengelolaan Sampah sebagai Bahan Bakar untuk Pembangkit Listrik Tenaga Sampah (PLTSa) dengan Sistem Strategic Partner”. Pelaksanaan Sosialisasi pada Rabu, 12 Agustus 2020 di Kantor Dinas Lingkungan Hidup Kab. Pangkep dengan peserta Sosialisasi yaitu perwakilan beberapa bank sampah di Kab. Pangkep. Adapun materi yang dijelaskan yaitu terkait potensi sampah sebagai bahan bakar untuk PLTSa khususnya jenis sampahnya serta proses PLTSa secara sederhana, kemudian dijelaskan peluang strategic partner dalam mengimplementasikan PLTSa, serta menunjukkan beberapa video proses PLTSa dan keberhasilan beberapa kota besar seperti Surabaya dalam menerapkan PLTSa yaitu PLTSa di taman Bratang yang merupakan salah satu PLTSa dengan sistem thermal dan PLTSa Benowo dengan sistem sanitary landfill.
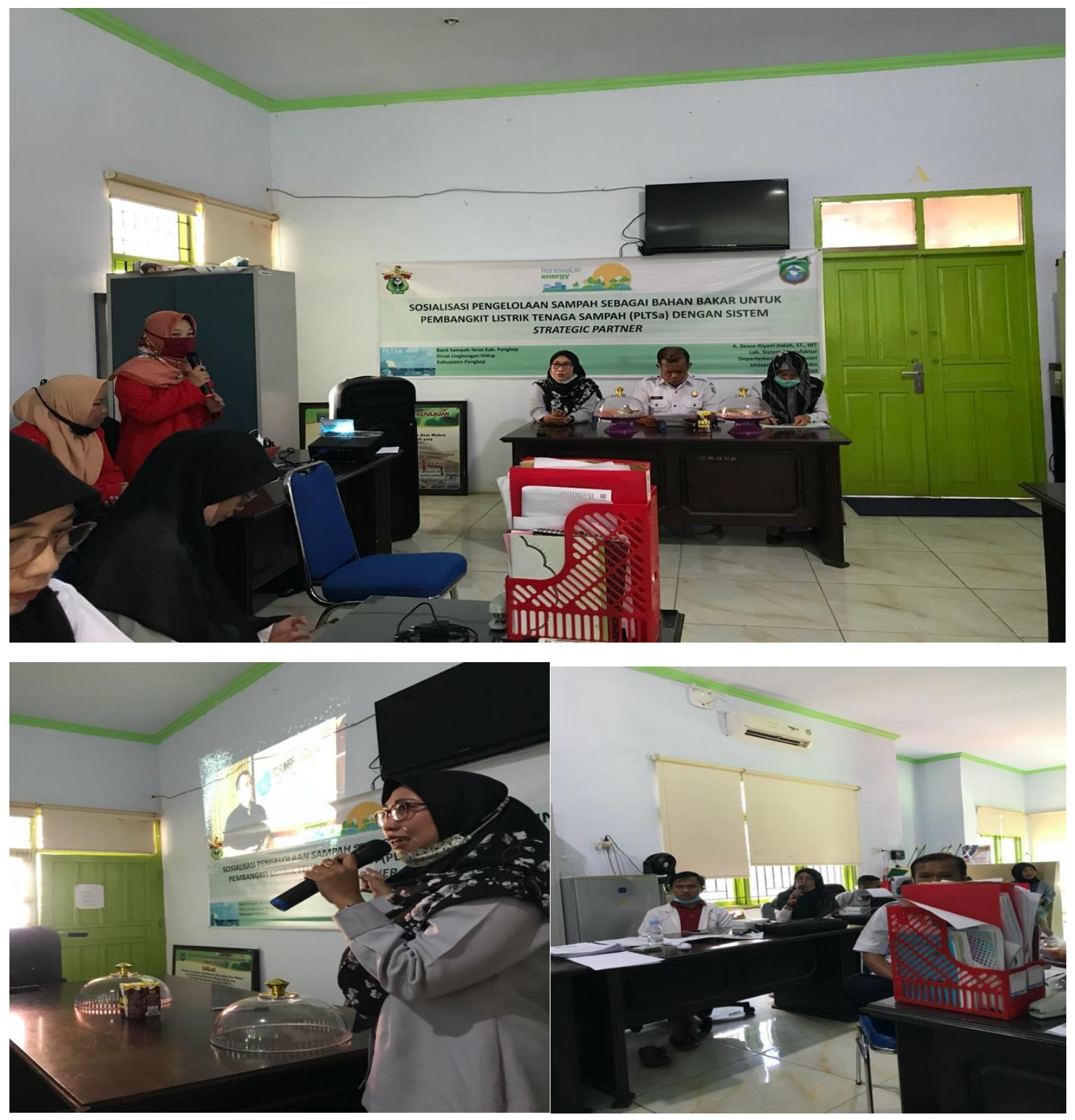

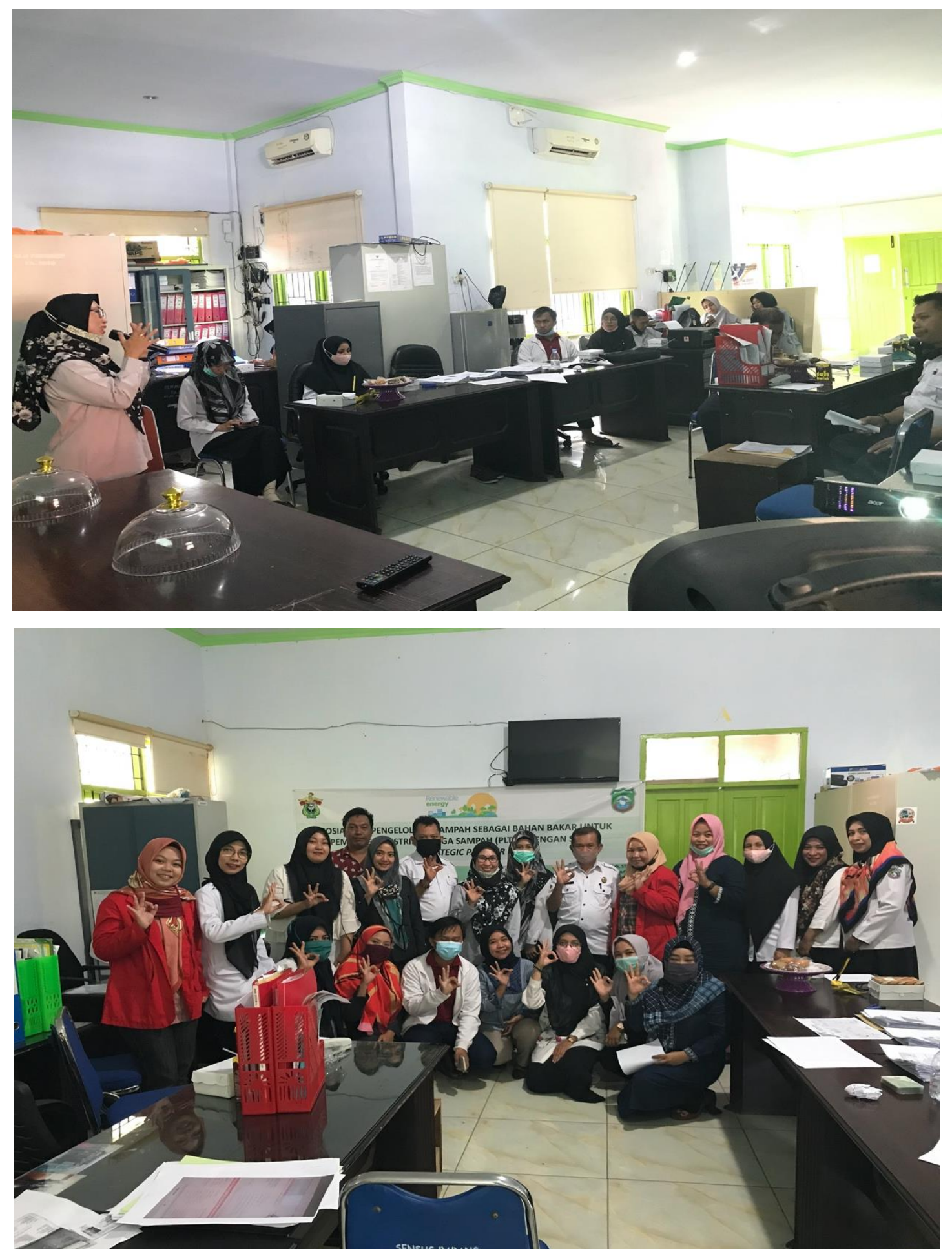

Gambar 3. Kegiatan sosialisasi di Dinas Lingkungan Hidup Kab. Pangkep 


\section{Hasil dan Diskusi}

Kegiatan sosialisasi ini diikuti oleh perwakilan beberapa bank sampah di Kab. Pangkep. Sebagian kecil peserta telah mengetahui potensi dari sampah yang dapat dijadikan bahan bakar namun mereka belum mengetahui secara mendalam terkait potensi dan sistem PLTSa yang dapat diterapkan. Dari hasil diskusi dengan pihak bank sampah dan Dinas Lingkungan Hidup Kab. Pangkep bahwa dalam menerapkan PLTSa di Kab. Pangkep harus dilakukan terlebih dahulu studi kelayakannya mulai dari potensi sampah yang dihasilkan sebagai bahan baku PLTSa hingga pada kemungkinan besar kapasitas listrik yang dapat dihasilkan. Dan hingga saat ini pihak Dinas Lingkungan Hidup mengalami kendala terkait uji kelayakan dan mengharapkan pihak akademisi yang bersedia menjalin kerja sama terkait melakukan uji kelayakan PLTSa di Kab. Pangkep. Mulai dari analisis bahan baku, kapasitas yang dapat dihasilkan, hingga pada instalasi mesin yang digunakan pada PLTSa. Maka dengan demikian peluang kerjasama Dinas Lingkungan Hidup Kab. Pangkep untuk melakukan uji kelayakan terkait penerapan PLTSa di Kab. Pangkep sangat terbuka lebar.

\section{Kesimpulan}

Penumpukan sampah merupakan salah satu masalah yang cukup serius yang perlu untuk ditanggulangi. Salah satu cara untuk mengurangi volume sampah adalah dengan memanfaatkan sampah sebagai sumber energi salah satunya adalah menjadi bahan bakar listrik untuk PLTSa. Namun pengetahuan masyarakat terkait potensi sampah menjadi bahan bakar listrik masih sangat minim. Oleh karena itu, kegiatan sosialisasi merupakan salah satu langkah yang dilakukan untuk memberi pemahaman kepada masyarakat pada umumnya dan pengelola sampah secara khususnya untuk mengetahui potensi pemanfaatan sampah menjadi bahan bakar PLTSa dengan mekanisme strategic partner.

\section{Ucapan Terima Kasih}

Ucapan Terima Kasih kepada semua pihak sehingga kegiatan pengabdian masyarakat Labo Based Educatian (LBE) dapat terlaksana dengan baik, terutama kepada : Fakultas Teknik atas penyelenggaraan kegiatan pengabdian masyarakat, Dinas Lingkungan Hidup Kab. Pangkep dan Ketua Bank Sampah Kab. Pangkep atas kerjasama yang baik selama berlangsungnya kegiatan ini, dan mahasiswa yang telah membantu terselenggaranya kegiatan pengabdian.

\section{Daftar Pustaka}

Sihite, A. S. F., 2018. Studi Pengolahan Sampah untuk Bahan Bakar Pembangkit Listrik Tenaga Sampah Mini di Kawasan Medan Sunggal, Medan: Universitas Sumatera Utara.

Monice \& Perinov, 2016. Analisis Potensi Sampah Sebagai Bahan Baku Pembangkit Listrik Tenaga Sampah (PLTSa) di Pekanbaru. Jurnal Sain, Energi, Teknologi \& Industri, Volume 1, pp. 9-16.

Indonesia, P. R., 2018. Peraturan Presiden Republik Indonesia Nomor 35 Tahun 2018 tentang Percepatan Pembangunan Instalasi Pengolah Sampah Menjadi Energi Listrik Berbasis Teknologi Ramah Lingkungan, Jakarta: Sekretariat Kabinet RI.

Mulyono, B., 2018. Kebijakan Pembelian Listrik PLTSa oleh PT PLN (Persero), Tangerang: Divisi Energi Baru dan Terbarukan Direktorat Pengadaan Strategis 1. 